\title{
Mitral valve abnormalities in patients with right ventricular pressure overload Analysis by real time cross sectional echocardiography
}

\author{
SEIKI NAGATA, YUNG-DAE PARK, NORIFUMI NAKANISHI, SHINTARO BEPPU, \\ HIROSHI SAKAKIBARA, YASUHARU NIMURA
}

From the National Cardiovascular Centre, Department of Medicine, Division of Cardiology and Research Institute, Osaka, fapan

SUMMARY Abnormalities of the mitral valve in patients with pulmonary stenosis, tetralogy of Fallot, and pulmonary hypertension with right ventricular pressure overload were studied by real time cross sectional echocardiography. Dislocation of the anterior and posterior mitral leaflets at the coaptation zone in systole was present in 16 of 46 cases: nine of $11(82 \%)$ cases of pulmonary hypertension, four of $20(20 \%)$ cases of tetralogy of Fallot, and three of $15(20 \%)$ cases of pulmonary stenosis. The incidence was highest in patients with pulmonary hypertension. In eight of the 16 patients with mitral valve lesions, mitral regurgitation was seen on left ventriculograms or cross sectional Doppler echocardiograms. The dislocation was located near the posteromedial commissure of the anterior mitral leaflet in all cases. These findings are similar to the mitral valve abnormalities seen in patients with secundum atrial septal defect, and therefore may be due to a common cause. No relation could be found between the left ventricular deformity index and the incidence of dislocation of the mitral leaflets. Thus, the reason why this mitral valve abnormality occurs in conditions with right ventricular pressure overload could not be established.

It is well known that secundum atrial septal defects are often associated with mitral regurgitation. ${ }^{12}$ The causal relation is probably expansion of the right ventricle due to the right ventricular volume overload, which deforms the left ventricle, thus causing the coaptation zone of the mitral valve to become distorted and thereby lead to mitral regurgitation. ${ }^{3}$

In this study mitral valve abnormalities causing secondary non-rheumatic mitral regurgitation were examined in patients with right ventricular pressure overload due to pulmonary stenosis, tetralogy of Fallot, and pulmonary hypertension.

\section{Patients and methods}

Forty six patients with right ventricular pressure overload, aged $\geqslant 16$ years, were examined by real time cross sectional echocardiography between May 1978

Requests for reprints to Dr Seiki Nagata, Division of Cardiology, Department of Medicine, National Cardiovascular Centre, Fujishirodai 5-125, Suita, Osaka 565, Japan.

Accepted for publication 6 March 1984 and July 1982 (Table 1). Fifteen had pulmonary stenosis, 20 tetralogy of Fallot, and 11 pulmonary hypertension. The underlying causes of pulmonary hypertension were primary pulmonary hypertension in three patients, pulmonary embolism in seven, and cor pulmonale in one. Twenty three healthy volunteers were studied as control subjects. Thirty seven of the 46 subjects underwent cardiac catheterisation.

\section{ECHOCARDIOGRAPHY}

The echocardiographs used were the Toshiba SSH$11 \mathrm{~A}$ and SSH-40A models. Cross sectional echocardiograms were recorded on an $8 \mathrm{~mm}$ cine film and analysed.

A mitral valve abnormality was diagnosed if dislocation of the anterior and posterior mitral leaflets was present at the coaptation zone on the echocardiograms (Fig. 1). ${ }^{24}$ The degree of dislocation was assessed by measuring the distance of the displacement at the coaptation zone. A dislocation of $\leqslant 5 \mathrm{~mm}$ was graded as 1 , of $\leqslant 10 \mathrm{~mm}$ as 2 , and of $\geqslant 11 \mathrm{~mm}$ as 3 . Analysis was performed by two independent observers. The degree of dislocation was different at five sites in four 
Table 1 Incidence of mitral valve abnormality in relation to lefi ventricular deformity index in study patients and healthy control subjects

\begin{tabular}{|c|c|c|c|c|c|c|}
\hline \multirow[t]{2}{*}{ Diagnosis } & \multirow{2}{*}{$\begin{array}{l}\text { No of } \\
\text { patients }\end{array}$} & \multicolumn{2}{|c|}{ Age (yr) } & \multicolumn{2}{|c|}{ Cardiac catheterisation } & \multirow{2}{*}{$\begin{array}{l}\text { No }(\%) \text { of patients with } \\
\text { abnormality }\end{array}$} \\
\hline & & Range & Mean & $\begin{array}{l}\text { No of } \\
\text { parients }\end{array}$ & $\begin{array}{l}\text { Mean } R V \text { systolic } \\
\text { pressure (mim } H g)\end{array}$ & \\
\hline $\begin{array}{l}\text { Pulmonary stenosis } \\
\text { Tetralogy of Fallot } \\
\text { Pulmonary hypertension } \\
\text { Healthy subjects }\end{array}$ & $\begin{array}{l}15 \\
20 \\
11 \\
23\end{array}$ & $\begin{array}{l}16-56 \\
16-50 \\
23-70 \\
15-68\end{array}$ & $\begin{array}{l}34.6 \\
33 \cdot 2 \\
50.3 \\
34.5\end{array}$ & $\begin{array}{l}11 \\
15 \\
11\end{array}$ & $\begin{array}{l}89.1 \\
93.5 \\
57 \cdot 1\end{array}$ & $\begin{array}{l}3(20) \\
4(20) \\
9(82)\end{array}$ \\
\hline
\end{tabular}
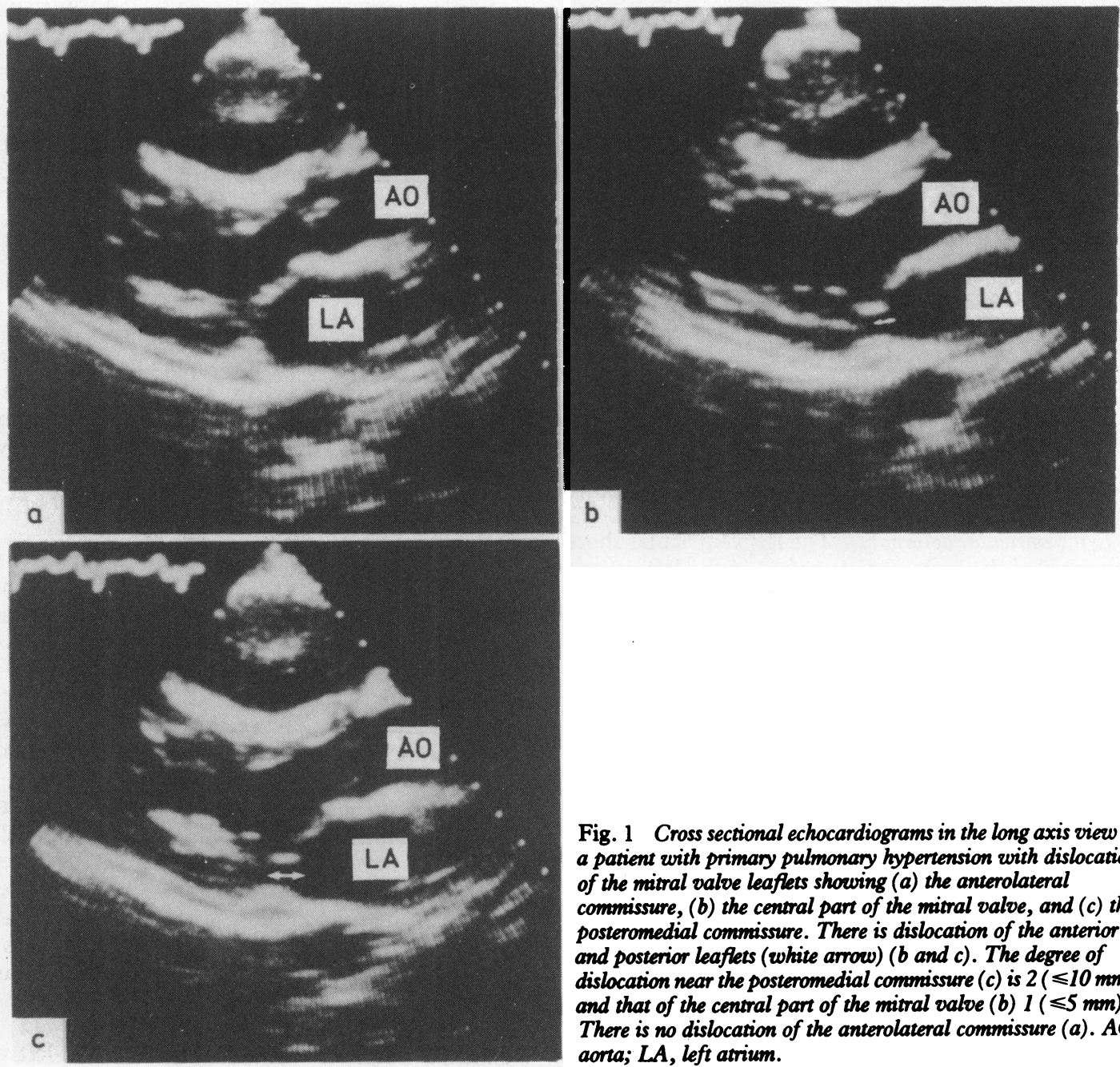

Fig. 1 Cross sectional echocardiograms in the long axis view in a patient with primary pulmonary hypertension with dislocation of the mitral valve leaflets showing $(a)$ the anterolateral

commissure, (b) the central part of the mitral valve, and (c) the posteromedial commissure. There is dislocation of the anterior and posterior leaflets (white arrow) ( $b$ and $c)$. The degree of dislocation near the posteromedial commissure (c) is $2(\leqslant 10 \mathrm{~mm})$ and that of the central part of the mitral valve $(b) 1(\leqslant 5 \mathrm{~mm})$. There is no dislocation of the anterolateral commissure (a). AO, aorta; $L A$, left atrium. 

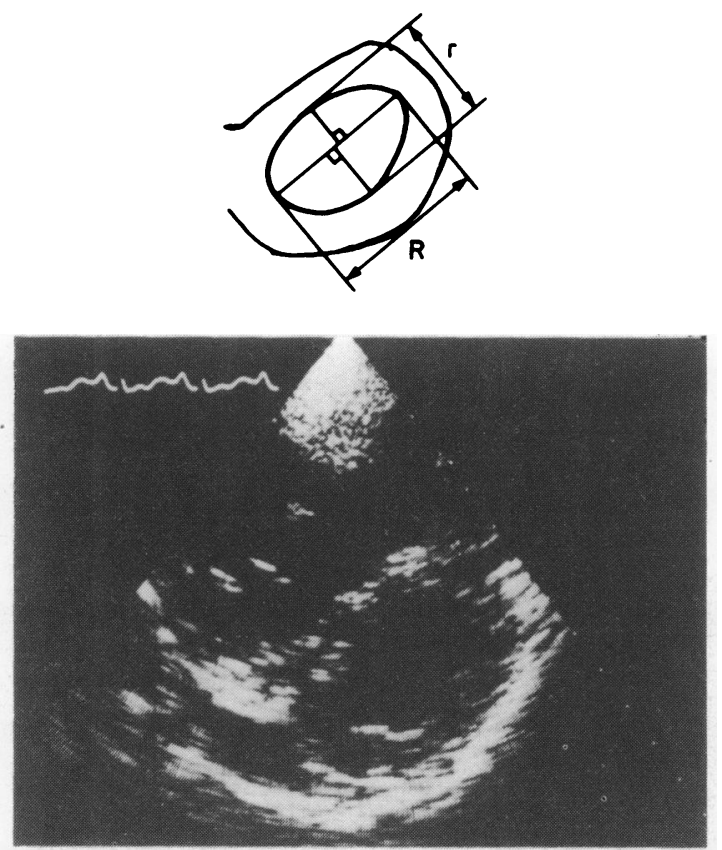

Fig. 2 Cross sectional echocardiogram showing the evaluation of left ventricular deformity in the short axis view of the endocardial surface of the left ventricle at the chordal level during end diastole and end systole. Diagram: The long axis of the left ventricle $(R)$ and the sum of the maximum values of the vertical lines extending to both sides from this axis $(r)$ were used to calculate the r: $R$ ratio, termed the deformity index.

patients by independent observers. In these cases, the lower grade of dislocation was used.

Left ventricular deformity - The left ventricular short axis view of the endocardial surface of the left ventricle at the chordal level was used to determine the

Table 2 Site and grade of dislocation of mitral valve leaflets

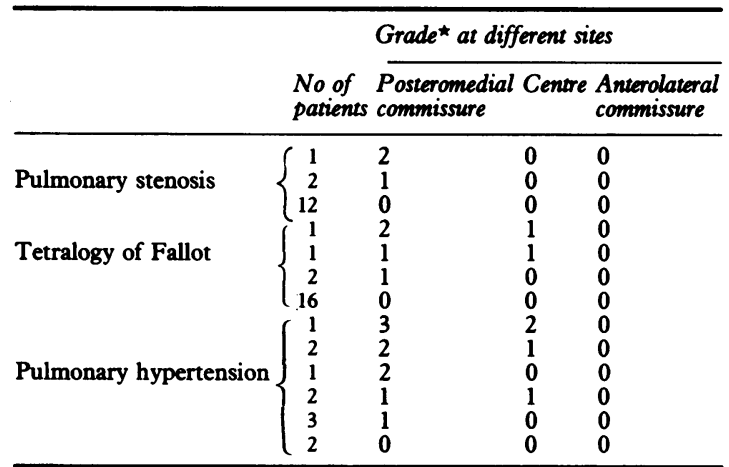

$\star^{*}$ Grade $1, \leqslant 5 \mathrm{~mm}$; grade 2, 6-10 mm; grade 3, $\geqslant 11 \mathrm{~mm}$. index for left ventricular deformity. In patients with right ventricular pressure overload the ventricular septum was pushed towards the left ventricle in the short axis view. As a result the left ventricle appeared flattened. The degree of deformity of the left ventricle was expressed as the left ventricular deformity index calculated as the ratio of $r: R$, where $R$ (long diameter) is the maximum diameter nearly parallel to the ventricular septum and $\mathbf{r}$ (short diameter) the sum of the maximum diameters extending on both sides from the long diameter (Fig. 2). The deformity index was calculated in the end diastolic and end systolic phases. Since the endocardium in the left ventricular short axis view was not visible in 13 of 46 patients, the relation between the left ventricular deformity and mitral valve abnormality was determined in only 33 cases.

Mitral regurgitation was assessed by left ventriculography or cross sectional Doppler echocardiography, as described. ${ }^{5-7}$

\section{STATISTICAL ANALYSIS}

The data were analysed by the $\chi^{2}$ test and unpaired $t$ test. Differences were considered to be statistically significant when $\mathrm{p}<0.05$.

\section{Results}

Incidence of dislocation-Dislocation of the mitral leaflets was present in 16 of 46 patients: in three of 15 cases of pulmonary stenosis, in four of 20 cases of tetralogy of Fallot, and in nine of 11 cases of pulmonary hypertension. The incidence of dislocation was significantly higher in patients with pulmonary hypertension than in those with tetralogy of Fallot or pulmonary stenosis $(p<0.002)$ (Table 1$)$.

Sites of dislocation-The dislocation affected the posteromedial commissure of the anterior leaflet in all 16 patients. In seven patients it also affected the central part from the posteromedial commissure of the anterior leaflet. No patients had dislocation of the posterior leaflet only (Table 2). In eight of the 16 patients mitral regurgitation was evident on left ventriculograms or cross sectional Doppler echocardiograms.

The left ventricular deformity index estimated during end diastole and end systole was compared in healthy volunteers and the study group (Fig. 3). Deformity was present in all patients in the study group except during end diastole in those with tetralogy of Fallot. Among the study group, however, there was no significant difference in the deformity index during any time phase.

Left ventricular dimensions-There was no significant difference in the diameter of the left ven- 

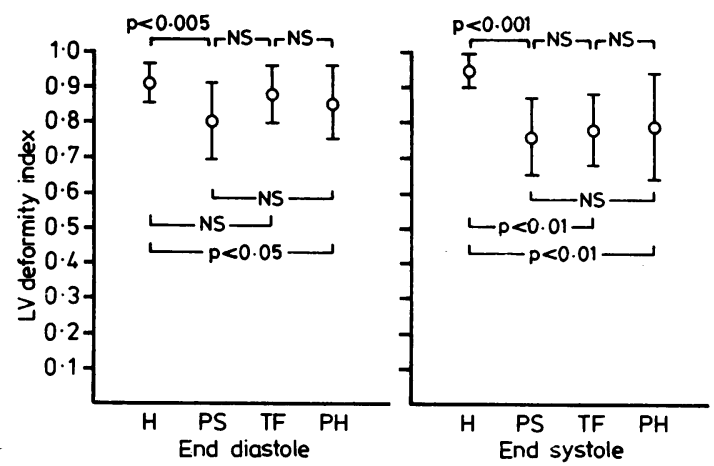

Fig. 3 Mean (SD) values of left ventricular deformity index in healthy subjects $(H)$, and in patients with pulmonary stenosis (PS), tetralogy of Fallot (TF), and pulmonary hypertension $(P H)$ at end diastole and end systole.



Fig. 4 Left ventricular ( $L V$ ) dimensions by $M$ mode echocardiography in patients with pulmonary stenosis (PS), tetralogy of Fallot $(T F)$, and pulmonary hypertension $(P H)$. (O) patients with mitral valve abnormality, $(O)$ patients without mitral valve abnormality.

tricle measured in $M$ mode echocardiograms during the end systolic phase in the study group (Fig. 4).

\section{Discussion}

Recently, mitral valve abnormalities causing secondary non-rheumatic mitral regurgitation have been studied. In the present study, mitral valve abnormalities in patients with right ventricular pressure overload were analysed by cross sectional echocardiography.

The incidence of abnormalities of the mitral valve in secundum atrial septal defects due to right ventricular volume overload is reported to be as high as $50 \% .^{2}$ In the present study, however, the incidence was only $20 \%$ in patients with pulmonary stenosis and tetralogy of Fallot but $82 \%$ in patients with pulmonary hypertension. ${ }^{8}$ In patients with right ventricular pressure overload the degree of left ventricular deformity was similar during the end systolic phase in those with pulmonary stenosis, tetralogy of Fallot, and pulmonary hypertension. There were, however, differences in the incidence of dislocation of the mitral valve leaflets. Why the incidence differed when the degree of deformity was nearly the same is difficult to explain. One possible explanation is that pulmonary stenosis and tetralogy of Fallot are congenital heart diseases, whereas in pulmonary hypertension the right ventricular pressure overload is acquired. In pulmonary hypertension dislocation of the mitral valve leaflets occurs when the normally developed left ventricle, which appears round in the short axis view, is deformed by the right ventricular pressure overload, thus accentuating the spatial distortion of the mitral valve. In congenital right ventricular pressure overload, however, the mitral valve develops at the same time as there is right ventricular pressure overload and thus dislocation of the leaflets may occur less 'often.

In atrial septal defect, mitral valve dislocation usually occurs near the posteromedial commissure of the anterior mitral leaflet. In the present study in patients with right ventricular pressure overload with or without tricuspid regurgitation dislocation also occurred at the posteromedial commissure of the anterior leaflet. This suggests that mitral valve abnormalities occur in cases of right ventricular pressure overload by the same mechanism as in those of right ventricular volume overload. Tricuspid regurgitation was detected in $22 \%$ of the patients with pulmonary stenosis, $63 \%$ of those with tetralogy of Fallot, and $100 \%$ of those with pulmonary hypertension by cross sectional Doppler echocardiography or right ventriculography. Thus the original diseases and tricuspid regurgitation cause right ventricular enlargement which leads to dislocation of the leaflets.

Diseases with right ventricular overload are often accompanied by mitral valve abnormalities. Deformity of the left ventricle has, therefore, been regarded as one of the causes of these abnormalities. ${ }^{3910}$ Why they occur when the left ventricle is deformed has, however, not been explained. One explanation may be that the left ventricular deformity mainly causes displacement of the posterior papillary muscle, thus shortening the distance between the muscle and the valve ring, which results in distortion of the mitral valve. To confirm this theory, the distance between the posterior papillary muscle and the valve ring 
needs to be measured, but this is difficult at present.

In this study, no relation could be found between the left ventricular deformity index and the incidence of dislocation of the mitral leaflets. We could not, therefore, determine why this abnormality occurs in diseases with right ventricular pressure overload.

\section{References}

1 McDonald A, Harris A, Jefferson K, Marshall J, McDonald L. Association of prolapse of posterior cusp of mitral valve and atrial septal defect. Br Heart $\mathcal{F} 1971$; 33: 383-7.

2 Nagata S, Nimura Y, Sakakibara $H$, et al. Mitral valve lesion associated with secundum atrial septal defect. Analysis by real-time two-dimensional echocardiography. Br Heart f 1983; 49: 51-8.

3 Schreiber TL, Feigenbaum H, Weyman AE. Effect of atrial septal defect repair on left ventricular geometry and degree of mitral valve prolapse. Circulation 1980; 61: 888-96.

4 Nagata S, Sakakibara H, Mikami T, et al. Idiopathic mitral valve prolapse. Analysis by real-time twodimensional echocardiography. Fpn Circ $\mathcal{F} 1982$; 46: 369-76.
5 Miyatake K, Kinoshita N, Nagata S, et al. Intracardiac flow pattern in mitral regurgitation studied with combined use of the ultrasonic pulsed Doppler technique and cross-sectional echocardiography. Am F Cardiol 1980; 45: 155-62.

6 Miyatake K, Nimura Y, Sakakibara H, et al. Localisation and direction of mitral regurgitant flow in mitral orifice studied with combined use of ultrasonic pulsed Doppler technique and two dimensional echocardiography. Br Heart f 1982; 48: 449-58.

7 Kinoshita N, Nimura Y, Okamoto M, Miyatake K, Nagata S, Sakakibara H. Mitral regurgitation in hypertrophic cardiomyopathy. Non-invasive study by twodimensional Doppler echocardiography. Br Heart $\mathcal{f}$ 1983; 49: 574-83.

8 Goodman DJ, Harrison DC, Popp RL. Echocardiographic features of primary pulmonary hypertension. Am f Cardiol 1974; 33: 438-43.

9 Kambe T, Ichimiya S, Toguchi M, Hibi N, Fukui Y, Nishimura K. Cross-sectional echocardiographic study on the mitral valve prolapse associated with secundum atrial septal defect. Pre- and post-operative comparison. Fpn Circ F 1981; 45: 260-7.

10 Ballester M, Presbitero P, Foale R, Rickards A, McDonald L. Prolapse of the mitral valve in secundum atrial septal defect: a functional mechanism. Eur Heart $\mathcal{J}$ 1983; 4: 472-6. 